\title{
Knowledge Hoarding at a State University Library in Zimbabwe
}

\author{
Moses Mutage \\ National University of Science and Technology \\ Email: mmutage09@gmail.com
}

Peterson Dewah

National University of Science and Technology

Email: Dewahp@ukzn.ac.za peterson.dewah@nust.ac.zw

\begin{abstract}
Despite the need to bridge the knowledge gap introduced by technology, knowledge hoarding by library staff seems to affect service delivery at a state university library in Zimbabwe. The study employed a qualitative research approach in a case study design, informed by the interpretive paradigm. The target population of this study consisted of senior library management personnel and their subordinates. Maximal variation purposive sampling strategy was chosen to sample twenty-six library staff/ individuals that differ on some characteristics. Data were generated using interviews and observations. Key findings revealed that mistrust, unfair treatment, poor interpersonal relations, lack of recognition, and absence of a reward system induce knowledge hoarding and discourage library staff from sharing experiences. Furthermore, the study revealed that while librarians hoard knowledge as a security strategy for indispensability, hoarding knowledge has led to individualism and privatisation of knowledge. The study concluded that withholding of knowledge, for whatever reason, results in negative implications on the performance of new roles and service delivery. The study recommends that library staff should change from knowledge hoarding to sharing their knowledge; that the state library should implement a knowledge sharing policy; that the university library should reward knowledge sharing and recognize knowledge contributions from subordinates.
\end{abstract}

Keywords: Knowledge hoarding, knowledge management policy, knowledge sharing https://dx.doi.org/10.4314/udslj.v16i2.2

\section{Introduction}

The changing technological environment and innovations have altered traditional operations in academic libraries and calls for sharing knowledge about library processes among employees in order to perform new knowledge-based roles for better service delivery. Knowledge sharing is considered an important solution for academic libraries to improve service delivery (Poonkothai, 2016) but hoarding knowledge impedes collective organisational learning in academic libraries (Ajie, 2019). Connelly (2012) views knowledge hoarding as the active and intentional attempts by organisational members to withhold or conceal knowledge or information that has been requested by another person. In libraries, knowledge hoarding inhibits creativity and innovation that would match service delivery due to expanded library roles. According to Maponya (2004), the advent of the digital era posed many challenges among librarians such that knowledge hoarding has implications on the delivery of quality service. Libraries learn from experimenting with new 
knowledge (Makeyiso, 2013) but hoarding knowledge inhibits learning in organisations; this consequently affects the organisation's capability to adapt to changing market demands (Burmeister, Gerpott \& Fasbender, 2018). In libraries, sharing knowledge enhances problem-solving while withholding it impedes systematic problem solving and leads to repeated mistakes by operational librarians (Tahleho, 2016; Makeyiso, 2013). Ajie (2019) and Chipeta (2018) are of the view that withholding knowledge impedes the acquisition of innovative ideas that have potential to improve capabilities to perform well in various university libraries functions. Knowledge hoarding in libraries affects the free flow of new and creative ideas that lead to innovations and efficiencies in library performance (Ajie, 2019). Connelly (2012) and Mangold (2017) believe that knowledge hoarding is linked to interpersonal distrust which leads to deterioration of interpersonal friendships and relationships thereby inhibiting cooperation. Knowledge hoarding takes place among employees in various organizations including academic libraries with detrimental effect on the performance of organisations.

Knowledge hoarding affects service delivery in libraries especially in this technological era that requires librarians to become literate, acquire relevant skills to perform new roles and change ways of providing services to clients (Makeyiso, 2013; Mavodza \& Ngulube, 2010). Although librarians are challenged to develop themselves to meet the ever-changing needs of clients through sharing knowledge, there is a reluctance to share experienced information and knowledge among librarians (Ajie, 2019) yet knowledge hoarding among librarians does not come without consequences on the library operations and service delivery (Connelly, 2019). In libraries, knowledge hoarding promotes a culture of individualism which inhibits a collective effort towards the provision of good service delivery. Although libraries are in urgent need of acquiring unique skills and or upgrading them through sharing of experiences and competencies to accommodate their expanded roles, most experienced and knowledgeable members are reluctant to share their expertise (Connelly, 2019).

Withholding knowledge inhibits the transfer of capabilities to perform new roles by library staff thereby affecting collective efforts to deliver good services. Despite the need to bridge the knowledge gap introduced by the expansion of library roles through sharing experiences, the knowledge sharing attitudes between senior library management personnel and their subordinates at the public university under study is questionable. There seems to be a culture of individualism amongst library staff as evidenced by the variation of quality of services offered. In some cases, signs of disjointed team workmanship between library management personnel and their subordinates at this state university library manifest in the provision of services. This culture of individualism among library staff defeats the spirit of teamwork and collective contribution towards achieving improved service delivery to clients such as academics and students. It is clear that library management hoard new knowledge acquired from seminars and subordinates find it difficult to unlock this knowledge from their seniors. Consequently, this has attracted scientific enquiry.

This study was conducted at a state university library in Zimbabwe. The study sought to investigate knowledge hoarding by library management personnel and their subordinates and its effects on the service delivery of this public university library. Specifically, the study sought to: establish the effects of employee relations on knowledge hoarding among library staff of this state university library; assess the extent to which the university library staff are motivated to share knowledge; determine the attitude of state library staff towards knowledge hoarding and determine the extent to which knowledge hoarding impact the performance of the university library.

\section{Literature review}


A study by Chang, Xie and Feng (2017) found out that incivility on the part of supervisors induces bad relations between supervisors and subordinates which in turn impair knowledge sharing. Incivility in this context refers to an individual's threatening behaviour, rudeness, disrespectful treatment of others, and lacking good manners. At Kenya National Library, injustice done to employees by senior librarians led to distrust that influences knowledge hoarding and the unfair treatment of library staff by managers affects exchange relationships between them; employees do not feel valued, trusted, and recognized, leading to the feeling of being disconnected from the system (Tuitoek, 2014). Tang et al (2015) noted that ethical leadership influences positive knowledge sharing intentions in organisations while unethical leadership is associated with negative knowledge sharing behaviour which leads to withholding knowledge. Tuitoek (2014) observed that a culture of not sharing knowledge and being secretive invested by senior librarians causes bad relations that erode knowledge sharing morale at the library. Abe and Manson (2016) aver that poor leader to member exchanges do influence relationships that would encourage knowledge hoarding.

According to Rehman et al., (2010) organisational culture is a central and influential factor of knowledge sharing behaviour of individuals. Unsupportive organisational culture can be an influential driver of knowledge hoarding. Tuitoek (2014) observed that lack of knowledge sharing culture affects effective knowledge sharing between librarians. Leaders are the legal authorities of organisations who set the organisational culture that influences employee's knowledge sharing behaviour through articulating organisational values, norms, and social beliefs (Manus 2016).

Coercion cannot be used to induce knowledge sharing; rather, motivation and supportive leadership promote knowledge sharing through creating an environment that encourages and facilitates the sharing of knowledge. Top management is responsible for creating a conducive environment that encourages successful knowledge sharing (Yui \& Law 2012); for example, cultivating interpersonal trust and availing knowledge sharing rewards and recognition. Tuitoek (2014) found out that lack of senior management support has motivated knowledge hoarding attitudes. Top management involvement is a significant factor that drives employees towards knowledge sharing (Manus, 2016) and as such leaders should demonstrate fairness as a way of motivating employees to share knowledge (Mohmood, Alajmi \& Ahmed, 2018). Tan and Noor (2012) stress that for organisations to establish knowledge sharing culture, top management should at all costs support the initiative through shaping a conducive environment that facilitates and speeds up knowledge sharing.

Ugochukwu and Rajagopal (2018) singled out trust as one of the major factors that influence individual attitude towards knowledge sharing in organisations through building good interpersonal relationships. In addition, both intrinsic and extrinsic rewards have an influential impact on the knowledge sharing attitude of employees although intrinsic rewards have a greater impact as compared to extrinsic rewards (Razmerita, Kirchner \& Nielsen, 2016). Nevertheless, knowledge sharing is positively influenced by rewards expected from the activity and reputation building, while respect and recognition are strong motivators for knowledge sharing (Yiu \& Law, 2012). A negative attitude towards knowledge sharing is influenced by libraries that do not reward people who contributed to knowledge sharing (Nove \& Dyah, 2013). A culture of undermining staff inputs influences a negative attitude towards knowledge sharing (Tuitoek, 2014) yet a culture that supports knowledge sharing influences positive employee attitudes towards knowledge sharing (Makeyiso, 2013).

According to Yiu and Law (2012) losing ownership of knowledge weaken individual value and uniqueness in organizations. Organisations expect their employees to freely share 
their knowledge to gain sustainable competitive advantage (Connelly 2012) but the knowledge is, however, perceived by employees as the source of individual power which protects one's status in an organisation (Yiu \& Law, 2012); thus, sharing knowledge is perceived as a self-disarming process. Therefore, many employees are reluctant to share knowledge as a way of retaining individual power. Mohammad, Alajmi and Ahmed (2018) noted that to stimulate knowledge sharing in organisations, employees need to be rewarded through prizes, salary increase, commission, bonuses, promotion, and educational opportunities (extrinsic rewards) or benefits such as enjoyment or satisfaction gained from undertaking an activity (intrinsic) (Sajeva, 2014). Chipeta's (2018) study revealed that library staff in universities of Malawi was intrinsically motivated to share knowledge and they were not motivated by extrinsic rewards. Employees expect recognition and reputation more than any other benefits, hence extrinsic rewards are less effective as compared to intrinsic rewards (Susanty \& Wood, 2011). However, supportive leadership and a culture that appreciate knowledge sharing are effective motivator factors of sharing knowledge as compared to extrinsic ones (Makeyiso, 2013). Tahleho (2016) found out that at the University of Lesotho, librarians were motivated to share knowledge through promotional rewards and recognition. In contrast, librarians in the Federal University libraries in Nigeria were not incentivised to share knowledge with others and consequently, their level of knowledge sharing was described as below average (Onifade, 2015). Manus (2016) avers that organisational culture has a bearing on an individual's willingness to share knowledge.

A review of the literature revealed a dearth of studies on the relationship of knowledge hoarding between senior and junior staff and how this impacts the performance of university libraries in Zimbabwe. This study, therefore, sought to bridge that gap by establishing the impact of knowledge hoarding between senior management staff and subordinates on the performance of a state university library in Zimbabwe.

\section{Theoretical framework}

This study is based on the social exchange theory by Blau (1964) which suggested that knowledge sharing is a social exchange process where the willingness to share knowledge is highly dependent on future returns reciprocally. According to the social exchange theory distrust among employees and a perceived low level of future returns regulates the spirit of knowledge hoarding amongst individuals. Employees tend to hoard their knowledge if they have a feeling that there will be no returns or benefits from such an interaction. Employees always want to balance the exchange relationship based on the norm of reciprocity. If one part tends to benefit more than the other, the process will trigger the behaviour of hoarding knowledge to balance the behaviours between the two parties. Knowledge sharing only becomes binding when both parties are willing to contribute benefits to each other or where there is an exchange balance between two parties. Ellahi and Mushtaq (2011) noted that employees do not share knowledge due to insecure feelings and a perceived association between knowledge sharing and loss of opportunities hence they adopt attitudes of knowledge hoarding. Social exchange encourages people to interact regularly, sharing ideas and updates of work which will ensure a collective effort towards good service delivery.

\section{Methodology}

Anchored on the interpretivist paradigm, the qualitative research method was adopted for this research in order to get a deeper insight and understanding of knowledge hoarding and its impact on the performance of libraries. The target population of this study included six senior library management personnel and twenty junior staff. Maximal variation sampling strategy was chosen since the researchers sampled individuals that differ on some characteristics or trait, for instance age group. The purposive sampling technique was 
therefore used to select senior library staff and junior staff who would be able to convincingly answer questions about knowledge hoarding in the university library. Senior managers are the strategic policymakers for the library and they ensure policy implementation for the success of the library while junior library staff are operational staff who perform daily duties of the library. Data were gathered through interviews and observations over one month, and notes were taken. The researchers managed to interview sixteen librarians out of the twenty-six targeted participants, where face-to-face interviews were conducted with nine participants, while seven responded through filling in the openended questions on online questionnaires. While the name of the university is withheld for ethical reasons the participants of this study were given codes to maintain confidentiality and anonymity that is SM 1-6 for senior management staff and JS 1-10 for junior staff. Data was then analysed and presented thematically. The researchers did not manage to generate data from the principal officer of the library as planned due to their tight schedule during the data collection period.

\section{Research Findings}

This section presents the findings of the study based on its research objectives.

\section{Employee relations and knowledge hoarding}

The first objective of this study was to establish how employee relations influence knowledge hoarding at this public university library. When asked about the influence of employee relations on knowledge sharing at this university, library interviewees responded as follows:

SM3: There is somehow mistrust between library staff at this university which have influenced the creation of groups and individualism especially between senior library staff and their junior counterparts. This has influenced both knowledge sharing and hoarding knowledge among library staff.

SM2: Knowledge is regarded as a source of power that puts one on a cutting edge above others in this competitive environment. Therefore, knowledge is not shared with peers who appear to be future competitors.

SM6: Some people do not want to see visibility and success of their colleagues therefore cliques may be formed based on values, beliefs let alone elements of competition thus inhibiting or allowing the flow of knowledge whichever is applicable. Some people are generally lazy. The hard-working ones naturally would associate together and share information as may spell benefits. Some people are naturally gossipers and may have the potential of passing on the information and these are usually excluded from the loop of knowledge sharing.

What is emerging is that library staff lacks team work as they have no trust in each other and end up creating informal circles which influence knowledge hoarding. The results revealed that trust influences who one shares their knowledge and experiences with.

Views below indicate that leader to subordinate interactions influence knowledge hoarding rather than sharing knowledge at the library: 
JS1: The senior to junior relations lead to hoarding knowledge about the expertise on how to operate the assistive equipment for the visually impaired students at disability library; knowledge about forthcoming library workshops; procedures manuals and manuals about cataloguing special library collections, theses, dissertations and other special publications which are not shared with operational staff but rather kept in management offices."

SM6: If a leader is accommodative and open to new ideas, the subordinate feels welcome and is free to engage with the leader - this breeds trust and thus knowledge sharing is fostered. However, where the leader is not welcoming then it may be difficult for the subordinate to open up on anything good or bad happening in the organisation- and this does not breed trust. The junior can hold onto the best of ideas or to an impending business challenge if the leader is unpredictable. This means if the junior makes an error related to work, chances are he/she will hide it until it surfaces on its own, but where the junior feels otherwise a report is made and a problem is arrested in good time and mistakes corrected perhaps through training, transfers or cautioning.

JS3: Junior staff members in this library are regarded as instruments of getting work done rather than being active members and contributors to the library team. Some senior members rather claim that junior staff know very little, and their contributions are valueless, hence in most cases junior staff's contributions are turned down and they suffer embarrassment.

About how peer to peer friendships influence knowledge hoarding in the library, participants responded as follows:

SM5: In this library peers relate well within circles. Where mutual trust and teamwork exist, knowledge is shared freely and where there is bad blood amongst peers individualism creeps in and people resist sharing their knowledge with peers whom they do not relate well with. For instance, a previous tensional relationship between a supervisor and subordinate has resulted in the creation of circles each with their sympathisers despite the matter having been "resolved" long back.

JS4: Knowledge is only shared within trusted friendships where one trusts other members that they will not compete for same positions with one in future.

JS1: Where there is lack of trust for future benefits from peers, people do not share their expertise.

\section{Staff unwillingness to share knowledge}

Chang, Xie and Feng (2017) noted that employees expect recognition as part of the system and fair treatment. Regarding staff members' unwillingness to share their experiences preferring to keep that important knowledge to themselves, comments in the interviews revealed that subordinates' contributions are looked at with contempt:

JS9 said: Contributions of junior library staff are not seriously considered by the superiors; this maybe simply because they are deemed juniors who lack experience and requisite knowledge. This has eroded individual confidence to share their 
experiences in performance meetings and led to withholding whatever knowledge possessed no matter how valuable to the issue at hand. Provision of platforms such as meetings to contribute to issues at hand and acknowledgement can be put in place to unlock the hoarded knowledge. Acknowledgement and consideration improve juniors' confidence to participate and share knowledge as they are sure that they will be listened to.

SM1 said: Staff members are being looked down upon by the seniors and their contributions are often rejected and criticised which has killed their confidence to share experiences."

SM6: The absence of stages to groom people contributes to lack of confidence and unwillingness to contribute knowledge. People should be given opportunities to role play, for instance to demonstrate how e-resources work.

Due to the vast knowledge about library processes that they acquired long back, the knowledgeable senior members have set norms and values to be followed by the rest of the staff in this library. Regarding communication between supervisor and subordinates, findings seem to suggest that subordinates take instructions and do what is said by the supervisor. Interviewees' responses were as follows:

JS5: During meetings supervisors' contributions are the only ones that are considered.

JS8: Juniors cannot be confident to share knowledge with their seniors who appear to have amassed all the required knowledge over the past years and also did not want to share this knowledge with junior counterparts.

In support of this finding, Manus (2016) points out that leaders are legal authorities of organisations who set the organisational culture that influences employee's knowledge sharing behaviour through articulating organisational norms and values. Indeed, culture influences how people behave in an organisation by determining how people see each other, what they expect from others as well as the quality of relations (Azhar, 2012).

Five participants outlined the factors that discourage them from sharing experiences and expertise with colleagues in the library as follows:

JS7: I am discouraged from sharing my experiences because other members are resistant to new knowledge and my contributions are always criticized.

SM1: Our library runs a tight ship where only top management voices count. Any contributions from junior staff are not entertained.

JS10: Managers do not want to recognize and give credit where necessary but rather reject contributions of their juniors which they, in turn, implement behind their back later as their inputs. This de-motivates me from sharing knowledge in future.

JS2: Poor grading system de-motivates me from sharing knowledge because I am always undermined and associated with not having important knowledge because I hold a junior position. 
SM6: Some people are reluctant to take action, for example, if one shares but there are no takers for a training course suitable to one category. I personally have encouraged people to do further studies providing them with benefits of doing that for example at Polytechnics, University and also MOOCS but people are reluctant to take up such. Sharing knowledge, experiences is blocked by colleagues' attitude and reluctance to participate as most look forward to monetary benefits instead of professional growth. In future I can't keep sharing related information.

The emerging trends are that knowledge sharing at this library is with trusted colleagues with whom good relations have been established, while knowledge hoarding is the practice among mistrusted members.

\section{Attitude of library staff towards knowledge hoarding}

When asked about the attitude of library staff towards knowledge hoarding, interviewees stated the following:

SM4: People have a negative attitude towards knowledge sharing as evidenced by partial knowledge sharing in the library facilitated by the availability of internet that facilitates information sharing.

SM6: Generally, the attitude is to keep to ourselves what we know and have acquired. Sharing knowledge after attending workshops, conferences etc. is not taking place. Members who would not have attended such events never get the chances to know about the deliberations unless if they initiate the move to enquire from attendees.

It seems there is silent competition among senior library staff where each one of them is strategically positioning themselves for higher positions. What seems to emerge is that seniors withhold knowledge as a strategy to be better than others during promotion time. Participants reported failure to enforce knowledge sharing due to the absence of a Knowledge Management Policy as the key reason for hoarding knowledge acquired from workshops or seminars:

SM4 said: There is no clear cut policy in this regard, which makes it mandatory that when one is funded by the university to attend a workshop, they must facilitate another workshop to share the newly acquired knowledge.

SM2 mentioned that: I am not compelled to share so I keep it to myself.

JS5 remarked: Knowledge hoarding is not a wrong practice because sharing is not mandatory, hence librarians do not share newly acquired knowledge.

JS4 said: Hoarding knowledge is the best way to maintain power, influence and job security.

SM1: The members of staff work on shift work bases making it difficult for people to work together as a team and this has rather encouraged individualism and knowledge hoarding.

SM6: Focus of the workshop or conference content may not be targeted for certain categories of staff. It is a waste of time giving feedback from a Research Data Management workshop to junior members of staff stationed at the entry point of our 
library with sole responsibility of verifying registration status of users intending to enter the library.

Participants were requested to provide reasons why they rarely share their experiences or assist those who request this knowledge. Findings indicate that staff hoard knowledge to protect their positions and interests and regard knowledge as a source of power. Therefore, withholding expertise makes them irreplaceable and indispensable to the organisation.

JS3: Knowledge is power, and sharing will be empowering your future competitor while disarming yourself.

SM2: I hoard knowledge so that I can always be consulted. Some colleagues want to be felt when they are not available because they are the only ones who know how to administer the institutional repository; maintain the library database software; and operate assistive machines for the disabled. Besides, I cannot equip someone with my expertise who will in turn become my biggest competitor in the future.

SM6: Those in need must identify those other members of staff that they believe know what they require and ask for assistance. There may not be means in place to get information from all staff. For instance, using a monkey survey, their specific needs can be identified. Through customised training, employees can be able to share their experiences.

The results indicated that individuals regard their work environment as competitive such that sharing knowledge is tantamount to equipping the competitor; therefore, they choose to hoard knowledge.

\section{The impact of knowledge hoarding on the performance of university library}

Regarding the effects of knowledge hoarding on the performance of university library, interviewees responded as follows:

SM2: It impedes acquisition of new delivery methods and capabilities to navigate technology systems that have influenced traditional operations of the library.

SM5: Knowledge hoarding results in stalling provision of services such as loaning and returning of library materials when the library system is down, and the knowledgeable individual is away.

JS9: It lowers the library standards such as a better move towards electronic resource access as people fail to pull in the same direction because other people feel they are not as appreciated as others when the electronic resource-based knowledge is not shared with them.

JS7: Knowledge hoarding results in underutilization of electronic resources where just a few people can make use of electronic resource databases and untapped knowledge bases.

JS6: Library management staff are better capacitated than any other staff because of being more experienced and their opportunity to attend workshops. By hoarding this knowledge triggers delayed service by juniors both unintentionally and intentionally as a way of revenging which will be blamed on seniors. 
SM4: Knowledge hoarding created some bottlenecks in the system as an individual's pace and progress of work are dictated by someone such as the pace of uploading library materials on the institutional repository which is set by the systems analyst who is knowledgeable in exploiting the KOHA system used when uploading materials, causing a feeling of not being in control of their own success which demotivates staff.

SM6: Libraries and staff don't develop because a lot of trends, developments, practices are taking place and shaping up daily, and globally, so, hoarding information is not a good idea because one may keep an idea that is going to be overtaken by events. In this digital era, if you share knowledge usually in return you will receive something related, but if you do not share you are shut out of a network and what you may have as the latest of ideas would actually be obsolete."

Knowledge hoarded is knowledge underutilized; as such, knowledge hoarding results in failure to take full advantage of electronic resources available in the library.

\section{Discussion of findings}

This section presents a discussion of research findings presented in the previous section.

\section{Employee relations and knowledge hoarding}

What emerged from the findings is that library staff lacks team work and lacks trust in each other indirectly leading to the creation of informal circles which influence knowledge hoarding. Hislop (2013 as cited in Saretsalo, 2015) noted that where there is tension between employees and the organisation they work for; employees may decide to withhold their knowledge. Trust influences who one shares their knowledge and experiences with. The poor supervisor to subordinate relationships caused by the unfair treatment of junior staff has eroded trust and belief in junior staff that they are important players of the library team, and their knowledge is significant towards the good performance of the library. These findings are consistent with Arain's (2018) observation that when exposed to unfair treatment and unjustified criticism, junior staff tend to develop a negative relationship with their supervisors and do not share their knowledge and experiences. Similarly, the findings corroborate Mohmood et al.'s (2018) observation that unfair treatment of employees demotivates them to share knowledge because it erodes trust and justice that unite social groups and encourage working together. When subjected to supervisor incivility employees develop negative emotions which inhibit motivation for knowledge sharing (Chang, Xie \& Feng 2017).

Peers in this university library share their knowledge with the expectations of reciprocation in future. These findings corroborate conclusions by Chipeta (2018) who studied knowledge sharing strategies in university libraries of Malawi and found out that reciprocal trust amongst peers and between junior and senior librarians have encouraged the free exchange of knowledge while distrust leads to withholding of knowledge. Interpersonal and informational injustice of employees is positively correlated to distrust among individuals which encourages knowledge hoarding (Schaap, 2018). The findings are in sync with Yiu and Law (2012) who aver that knowledge sharing cannot be fostered without an element of trust between two parties involved. The trends and findings of the current study support by Blau's social exchange theory in that people expect returns in respect of their shared knowledge. However, it has emerged in this study that the library employees lack team work 
and lack trust and all this negatively affect knowledge sharing which in turn has implications on service delivery.

\section{Staff unwillingness to share knowledge}

The findings in the current study indicate that there is a culture that believes in seniors knowing everything, not recognising and acknowledging subordinates as sources of innovation in the library. This is because subordinates are considered to be less experienced and possessing less important knowledge. Such perceptions have de-motivated them to share knowledge. Lwanga and Ngulube (2019) found out that recognition has a positive bearing on knowledge creation in academic libraries. The juniors lack confidence and belief in themselves when they compare themselves with their seniors who are more experienced and knowledgeable in various library processes such as information preservation, information organisation and security systems, cataloguing and classification as well as how to use the anti-plagiarism software (Turnitin). This has affected the confidence of juniors to share their perceived little experiences with long-serving senior library members. While unsupportive organisational cultures that do not recognize inputs of organisational members as valuable de-motivates knowledge sharing (Manus 2016), unjustified incivility from senior management members disunites organisational groups and cause distrust between members that can cause knowledge hoarding (Chang, Xie \& Feng, 2017).

Both poor and good relations exist between senior library management staff and their juniors and this has impact on sharing knowledge. Interpersonal trust forms the basis for good relationships between people where positive expectation about another person's behaviour is trusted (Yiu \& Law, 2012), thereby influencing positive knowledge sharing. The reasons for sharing and hoarding knowledge are attested to by Blau's (1964) social exchange theory, which posits that interpersonal distrust results in the creation of ineffective social exchange relationships that induce positive knowledge hoarding behaviour.

The findings indicated that seniors believe that only knowledge from the top senior officials is considered relevant for the smooth running of the library. This has undermined the subordinates' willingness to share knowledge. Yiu and Law (2012) point out that leadership where only top management voices are considered relevant results in low levels of information exchange and, the subordinates tend to withhold and hoard their knowledge. In some cases, juniors see their once criticized innovative ideas being implemented in future which further de-motivates them from sharing knowledge and experiences. The results agree with Yiu and Law (2012) that lack of recognition and appreciation from others induces behaviour and attitudes that can result in withholding knowledge. The findings of the study have implications for Blau's social exchange theory (Blau, 1964) in relation to knowledge hoarding in academic libraries. In line with this Lwanga and Ngulube (2019) observe that if academic libraries are to recognise the centrality of staff knowledge, it is critical that rewards, which include recognition, reassignments, promotions, training and pay, need to be streamlined in library policies.

\section{Attitude of library staff towards knowledge hoarding}

The researchers noted that library staff members have mixed feelings about knowledge hoarding. Most of the staff (both senior and junior) support the idea of withholding knowledge. It also emerged that knowledge hoarding in the library is indirectly encouraged by the absence of a knowledge-sharing policy. Webster et al (2008) observed that people 
fear the loss of superiority and knowledge ownership; therefore, people develop a positive attitude towards knowledge hoarding. What emerges is that staff members are not bound by any regulation to share newly acquired knowledge with colleagues after attending workshops and seminars. Staff members, therefore, keep to themselves the acquired knowledge on exploiting library electronic resource platform or databases and the adopted Resource Description and Access (RDA) cataloguing system. They consider all this acquired knowledge to be personal achievements.

What seems to emerge is that library staff felt that knowledge hoarding has more benefits to them than knowledge sharing; hence, they have developed tendency to hoard knowledge as a strategy for job security and to maintain positions, and gain unique power that enables individuals' authority to be felt in the library, confirming Webster et al (2008) who opined that knowledge hoarding behaviour can be influenced by the desire to maintain power. While Yiu and Law (2012) noted that people are discouraged to share knowledge because sharing is perceived as weakening one's corporate position in an organisation Tuitoek (2014) regards knowledge sharing as a self-disarming process in a competitive organisational environment since knowledge is viewed as a source of power. According to the Balu's social exchange theory a perceived low level of future returns regulates the spirit of knowledge hoarding amongst individuals. In the current study library employees tend to hoard their knowledge because they felt that there are no returns or benefits from sharing what they know.

\section{The impact of knowledge hoarding on the performance of university library}

A phenomenon that emerged from the findings was that withholding knowledge at the library hinders the provision of quality service that requires exploiting the KOHA library system such as loaning materials when it is down, and the knowledgeable person is not available. When one withholds either explicit knowledge in the form of electronic access procedure manuals, classification, and cataloguing manuals or tacit knowledge such as expertise on anti-plagiarism software needed by students and lecturers, other library staff will not be able to maintain a high quality of service in the absence of the knowledgeable individual. The findings corroborate Connelly's (2012) view that knowledge hoarding has never been shown to be a brighter side for enhancing good service delivery in organisations. This implies that hoarding knowledge would impair a collective move towards the provision of excellent services. Lack of knowledge sharing initiatives is strongly linked to poor service delivery (Azhar, 2012). Unless knowledge is shared among all staff, it remains packed in few individual minds leading to underutilization of electronic resources, hence negative effects on service delivery in this library. Connelly (2012) points out that knowledge hoarding has serious implications on organisational performance such as low levels of creativity, innovation and destruction of interpersonal relationships which all lead to bad workmanship and poor service delivery. According to Blau (1964) social exchange encourages people to interact regularly, sharing ideas and updates of work which will ensure a collective effort towards good service delivery.

\section{Implications of the research}

The current study has some managerial, practical and research implications that should be considered when interpreting the findings. The knowledge hoarding study was conducted on purposively selected 26 participants consisting seniors and their juniors. Future research should extend to all members of staff who work in the state university libraries. Further research on knowledge mapping in the state library will help to survey and locate where knowledge lies in the libraries. The other managerial implication is that performance gaps 
require that the state library management to put up a proper induction programme where new employees in the university libraries learn about its culture and inculcate a culture of knowledge sharing rather than conceal knowledge. Concealing knowledge impacts on service delivery.

\section{Conclusion}

The study established that both senior and junior library staff practice knowledge hoarding in this public university library. Their reasons for withholding knowledge included unfair treatment, fear of losing power and status, distrust, and lack of knowledge management policy, among others. Staff de-motivation, mistrust, autocratic leadership styles and undermining juniors were major factors that contribute to poor/bad relations which in turn induce knowledge hoarding. Key findings indicate that lack of recognition, rejection of knowledge contributions, criticism and poor grading systems were major factors that motivate knowledge hoarding and have implications on the performance of new library roles. It was also concluded that subordinates always want to balance social exchange with their superiors. Therefore, if supervisors tend to hide their knowledge it will stimulate knowledge hoarding behaviour in their juniors to balance social exchange. Social exchange theory can be used as a basis for eliminating knowledge hoarding. When a subordinate feels that their supervisor is hiding knowledge from them, they tend to balance the social exchange by refusing to divulge their experiences to them.

\section{Recommendations}

To improve service delivery in this public university library, the study makes the following recommendations:

i. The University Library Management should professionally resolve library employee conflicts so that there is a cordial work relationship that does not induce knowledge hoarding.

ii. The library management should advocate for a culture that promotes respect and fair treatment of all library staff to shape interpersonal trust and rebuilding of good relations between senior library management staff and their juniors. This then boosts the desire to share knowledge and avoid withholding knowledge and experiences.

iii. The University library should adopt and implement an appropriate knowledge management policy to discourage knowledge hoarding and formalize knowledge sharing across the library staff. Enforcing knowledge sharing policy, in particular, will make it mandatory to organise internal workshops that orient other library staff members about newly acquired knowledge from external workshops for which participation was organised and funded by the university. This discourages the privatisation of knowledge.

iv. Furthermore, the university library should organise different reward packages to incentivise knowledge sharing to activate the desire to share rather than hoard knowledge. 
v. To unlock innovative ideas residing in individual minds that can improve the performance of the library, the university library management should budget time for physical socialisation and social networking to encourage open discussions between senior and junior staff.

vi. Senior library staff should recognize and appreciate any knowledge contributions from the library staff regardless of positions.

\section{References}

Abe, I. I. \& Mason, R.B. (2016). The role of individual interpersonal relationships on work performance in the South African Retail Sector. Problems and Perspectives in Management, 14(2), 192-200. http://dx.doi.org/10.21511/ppm.14 (2-1).2016.08

Ajie, I. (2019). Issues and prospects of knowledge sharing in academic libraries. Library Philosophy and Practice (e-journal), paper 2521. Retrieved from https://digitalcommons.unl.edu/libphilprac/2521

Arain, G. A. (2018). Top-down knowledge hiding in organizations. Journal of Business Ethics, 164(3), 611-625.

Azhar, N. H. B. B. (2012). Motivation factors on knowledge sharing among public sector organisations in Malysia. Retrieved from: https://core.ac.uk/download/pdf/16515334.pdf.

Blau, P. M. (1964). Exchange and Power in Social life. John Wiley. https://doi.org/10.4324/9780203792643

Burmeister, A., Fasbender, U., \& Gerpott, F. H. (2019). Consequences of knowledge hiding: The differential compensatory effects of guilt and shame. Journal of Occupational and Organizational Psychology, 92(2), 281-304. https://doi.org/10.1111/joop.12249

Chang, L. Xie, W. \& Feng, T. (2017). How does supervisor incivility impair employees' knowledge sharing: Evidence from Chinese firms? International Journal and Business and Social Science, 8(10),201-213.

Chipeta, G. T. (2018). Knowledge Sharing Strategies in University Libraries of Malawi. $\mathrm{PhD}$ Thesis, University of KwaZulu-Natal, South Africa.

Connelly, C. E. (2012). Predictors of Knowledge Sharing in Organisations. Leadership \& Organisation 24(5),294-301.

Development Journal,

Connelly, C. E. (2019). Understanding knowledge hiding in organisations. Journal of organisational behaviour, 40 (7).779-782.

Ellahi, A. A. \& Mushtaq, R. (2011). Probing factors affecting knowledge sharing behaviour of Pakistani Bloggers. The Electronic Journal on Information Systems in Developing Countries, 45(6),1-14.

Lwanga, N.E. \& Ngulube, P., 2019. Nexus between reward culture and knowledge creation in selected academic libraries in Uganda. South African Journal of Information Management, 21(1), 1-8. https://doi.org/10.4102/ sajim.v21i1.1022

Makeyiso, N. (2013). Knowledge sharing practices in academic libraries with special reference to UNISA library. Master's dissertation, University of Cape Town, Cape Town, South Africa.

Mangold, S. (2017). Knowledge hiding in organizations: A multilevel analysis of antecedents and consequences. PhD thesis, Technischen Universität München, Munich, Germany.

Manus, P.M. (2016) Examining the Factors to Knowledge Sharing within an Organisational Context. Irish Academy of Management (IAM) - Doctoral Colloquium, Dublin 


\section{6.}

Maponya, P. M. (2004). Knowledge management practices in academic libraries: A case study of the University of Natal, Pietermaritzburg Libraries. SCECSAL Proceedings.

Mavodza, J. \& Ngulube, P. (2010). Exploring the use of knowledge management practices in an academic library in a changing information environment. South Africa Journal Libraries \& Information Science, 77(1),15-25.

Mohammad, M.T. F., Alajmi, S.A. \& Ahmed, E.A.R.D. (2018). Motivation factors towards knowledge sharing intentions and attitudes. Journal of Business administration, 9 (4). 110-126.

Nove, E.V.A. \& Dya, P (2013). Knowledge sharing in Libraries: A case study of knowledge sharing strategies in Indonesian university libraries, IFLA WLIC, 1-12

Onifade, F. N. (2015). Knowledge sharing among librarians in federal university libraries in Nigeria. Journal of Information and Knowledge Management, 5(3). 91-97

Poonkothai, R. (2016). Knowledge management as an important tool in library management. International Journal of Information Technology and Library Science, 5(1), 9-14.

Razmerita, L., Kirchner, K. \& Nielsen, P. (2016). What factors influence knowledge sharing in organizations? A social dilemma perspective of social media communication, Journal of Knowledge Management, 20 (6), 1225-1246. https://doi.org/10.1108/JKM-03-2016-0112

Rehman, M. Mahmood, A. K. B. Salleh, R., \& Amin, A. (2010). Review of Factors Affecting Knowledge Sharing Behavior. International Conference on E-business, Management and Economics, IPEDR (3), 223-227.

Sajeva, S. (2014). Encouraging knowledge sharing among employees: How reward matters. Procedia - Social and Behavioral Sciences, (156), 130 - 134.

Saretsalo, M. (2015). Factors influencing organisational Knowledge Management: Knowledge transfer in two local finance companies. Bachelor's dissertation, Turku University of Applied Sciences, Turku, Finland.

Schaap, N. (2018). Knowledge hiding of the leader and its effects on interpersonal and informational justice and employee performance. 10575553, Master's dissertation. Universiteit van Amsterdam, Amsterdam, Netherlands.

Susanty, A. I. \& Wood, P.C. (2011). The Motivation to Share Knowledge of the Employees in the Telecommunication Service providers in Indonesiain Proceedings of International Conference on Social Science and HumanityIPEDR, 5,IACSIT Press, Singapore

Tahleho, T. E. (2016). Improving Service Delivery at the National University of Lesotho Library through Knowledge Sharing. Master's thesis, University of South Africa, Pretoria, South Africa. Retrieved from https://uir.unisa.ac.za/handle/10500/21730

Tan, C. N. L. \& Noor, S.M. (2012). Knowledge management enablers, knowledge sharing and research collaboration: a study of knowledge management at research universities in Malaysia. Asian Journal of Technology Innovation, 21(2), 251-276.

Tang, P. M., Bavik, Y. L. Chen Y. F. \& Tjosvold, D. (2015). Linking ethical leadership to knowledge sharing and knowledge hiding: The mediating role of psychological engagement. IPEDR, 84, 71-76.

Tuitoek, C. C. (2014). Transfer of Tacit Knowledge among staff at the Kenya National Library Service. Master's Dissertation, Moi University, Nairobi Kenya.

Ugochukwu, E. D., \& Rajagopal, P. (2018). A conceptual framework on factors affecting 
knowledge sharing in Malaysian online retail platform. American Journal of Engineering Research, 7(5), 485-490.

Webster, J., Brown, G., Zweig, D., Connelly, C., Brodt, S., \& Sitkin, S. B. (2008). Beyond knowledge sharing: Withholding knowledge at work. In J. J. Martocchio (Ed.), Research in Personnel and Human Resources Management (pp. 1-37). Elsevier.

Yiu, M. \& Law, R. (2012). Factors influencing knowledge sharing behaviour: A social psychological view in tourism. Service Science, 3(2),11-41. 